\title{
Determining multi-species site use outside the protected areas of the Maasai Mara, Kenya, using false positive site-occupancy modelling
}

EMily K. MAdSEn and Femke Broekhuis

\begin{abstract}
Although protected areas are the basis for many conservation efforts they are rarely of an adequate size for the long-term survival of populations of large, wide-roaming mammals. In the Maasai Mara, Kenya, communally owned wildlife conservancies have been developed to expand the area available for wildlife. As these continue to develop it is important to ensure that the areas chosen are beneficial to wildlife. Using presence data for cheetahs Acinonyx jubatus, elephants Loxodonta africana, spotted hyaenas Crocuta crocuta, leopards Panthera pardus, lions Panthera leo and wild dogs Lycaon pictus, collected through interviews with 648 people living outside protected areas, we identify key wildlife areas using false positive site-occupancy modelling. The probabilities of site use were first determined per species based on habitat, distance to protected area, human presence and rivers, and these probabilities were then combined to create a map to highlight key wildlife areas. All species, except hyaenas, preferred sites closer to the protected areas but site use varied by species depending on habitat type. All six species avoided human presence. Leopards, elephants, lions and wild dogs preferred sites closer to rivers. The resulting combined map highlights areas that could potentially benefit from conservation efforts, including the expansion of wildlife areas, and areas where human development, such as a newly tarmacked road, could have an impact on wildlife.
\end{abstract}

Keywords Carnivores, false positive, interview data, Maasai Mara, mapping, occupancy modelling, protected areas, wildlife distribution

Supplementary material for this article is available at https://doi.org/10.1017/So030605318000297

\section{Introduction}

$\mathrm{P}$ rotected areas are the basis for many conservation efforts but in many cases are not sufficiently large to

Emily K. MADSEN ${ }^{*}$ (Corresponding author) Royal Veterinary College, 4 Royal College St, London, NW1 0TU, UK. E-mail: emadsen6@rvc.ac.uk

Femke Broekhuis $\dagger$ Kenya Wildlife Trust, Nairobi, Kenya

${ }^{*}$ Also at: The Zoological Society of London, Institute of Zoology, London, UK $\dagger$ Also at: Wildlife Conservation Research Unit, Department of Zoology, Tubney, UK

Received 6 September 2017. Revision requested 23 November 2017.

Accepted 8 February 2018. First published online 25 September 2018. maintain sustainable populations of many species (Stokes et al., 2010; Okello et al., 2016). Approximately $15.4 \%$ of the world's terrestrial area is now formally protected and in Kenya $8 \%$ of the land is protected as either a national park or reserve (Western et al., 2009). Nonetheless, 65$70 \%$ of the country's wildlife resides in unprotected areas where they are under threat (Western et al., 2009; Stolton et al., 2014) and so there is a desire to protect more land for wildlife (Republic of Kenya, 2013). The Maasai Mara in south-west Kenya, for example, is renowned for its annual migration of wildebeest Connochaetes taurinus and high densities of predators (Broekhuis \& Gopalaswamy, 2016; Elliot \& Gopalaswamy, 2017) but it is under increasing anthropogenic pressure. Since the 198 os there has been an increase in human population growth and fencing of private land outside protected areas (Lamprey \& Reid, 2004; Løvschal et al., 2017), which has resulted in wildlife populations decreasing by up to $75 \%$ in the 20 th century (Ogutu et al., 2011). The Maasai Mara National Reserve (hereafter the Reserve) covers $1,503 \mathrm{~km}^{2}$ and in the last 25 years surrounding areas have been put aside for wildlife to address these declines (Jandreau \& Berkes, 2016). These Community Wildlife Conservancies do not have the same status as the Reserve but are nonetheless recognized as being beneficial for wildlife (Stolton et al., 2014). In the conservancies landowners limit their use of resources and receive an income from tourist operators who pay for exclusive access (Jandreau \& Berkes, 2016). The development of conservancies has added c. 1,00o $\mathrm{km}^{2}$ of designated wildlife area to the Reserve, with a plan to increase this further (MMWCA, 2015). It is important to ensure that the areas chosen will benefit wildlife conservation, but land protection schemes can be costly and therefore planning needs to be based upon reliable information, from evidence-based research, to ensure cost-effectiveness (Zeller et al., 2011).

Land protection schemes are often based on species' occurrence because presence/absence data are easier and cheaper to collect than demographic data such as densities or whole population counts ( $\mathrm{Gu} \&$ Swihart, 2004). Information on wildlife presence can be collected with the help of local people, as they often have good knowledge of their local ecosystem and can provide insights into the distribution of wildlife (Turvey et al., 2015). Interview surveys can be a useful method of collecting this information because of cost-effectiveness and relatively simple logistics (Turvey et al., 2015; Petracca et al., 2018). However, the use 
TABLE 1 Environmental covariates hypothesized to influence the probability of habitat use, including the effect for each species.

Category and prediction
Human disturbance
All species will avoid human disturbance, with leopards
Panthera pardus showing the lowest level of avoidance
Proportion of fenced area
Elephants Loxodonta africana will avoid areas with a high
proportion of fencing
Habitat type preference
Cheetahs Acinonyx jubatus will select for open habitat but all
other species will select for semi-closed

\section{Protected areas}

Cheetahs, elephants, lions Panthera leo \& wild dogs Lycaon pictus will all have a preference for sites closer to protected areas; the effect will not be as strong for hyaenas Crocuta crocuta and leopards

Distance to rivers

Elephants, leopards, lions \& wild dogs will all select areas close to rivers
Source

Galanti et al. (2006), Athreya et al. (2013), Schuette et al. (2013), Loveridge et al. (2017)

Thouless \& Sakwa (1995), Loarie et al. (2009)

Creel \& Creel (1998), Carbone et al. (2005), Hopcraft et al. (2005), Galanti et al. (2006), Balme et al. (2007, 2017a,b), Bissett \& Bernard (2007), Kolowski \& Holekamp (2009),

Athreya et al. (2013), Broekhuis et al. (2013)

Woodroffe \& Ginsberg (1998), Galanti et al. (2006), Kolowski \& Holekamp (2009), Athreya et al. (2013), Schuette et al. (2013), Loveridge et al. (2017), Klaassen \& Broekhuis (2018)

Hopcraft et al. (2005), Balme et al. (2007; 2017a; 2017b), De Knegt et al. (2011), Cozzi (2012) of untrained individuals increases the chance that false positive detections will occur through, for example, misidentification or false reporting, resulting in an overestimation of occupancy (Royle \& Link, 2006; Petracca et al., 2018). This can be accounted for by focusing on easily recognizable species (Miller et al., 2011) and by using models that account for false positives (Royle \& Link, 2006).

Another factor that needs to be taken into account is detection probability. For example, presence/absence data may be biased towards habitats, such as open plains, where there is a high chance that an animal is detected. If this is not accounted for it may be impossible to correctly predict the areas that are most suitable for wildlife (Pulliam, 1988). The detection probability may also be influenced by the amount of time that a person spends outside, which is likely to vary with occupation (Turvey et al., 2015). Some studies have used the proportion of the year or other continuous covariates to account for effort (Zeller et al., 2011), however this is not possible if the interviewee is constantly resident in their area. If this is the case then categorical variables can be used. Additionally, assuming that non-detection equates to absence could result in a negative bias in occupancy estimates (MacKenzie et al., 2002, 2003). Imperfect detection can be accounted for by repeating surveys in each site, facilitating the calculation of detection probability using the detection history (MacKenzie et al., 2002). Failure to account for imperfect detection can lead to unreliable results and thus to ill-informed conservation decisions (MacKenzie et al., 2002, 2004). Both detection probability and imperfect detection can be accounted for using site-occupancy modelling (Pillay et al., 2011). These models have been expanded to account for false positives (Royle \& Link, 2006) and can therefore be used to provide robust results on species presence and distribution from interview data (Petracca et al., 2018).

Here we use interview data and false positive occupancy modelling to identify areas of high wildlife use outside the protected areas of the Maasai Mara, Kenya, to highlight priority locations for the potential expansion of conservancies. Basing management decisions on a single species may be unreliable because species show variation in behavioural plasticity when faced with threats (Woodroffe, 2000) so we used a multi-species approach focused on six large mammals: cheetahs Acinonyx jubatus, elephants Loxodonta africana, spotted hyaenas Crocuta crocuta, leopards Panthera pardus, lions Panthera leo and wild dogs Lycaon pictus. We focused on five carnivores because they can have wide-ranging, keystone ecological effects, and the protection of intact carnivore guilds is therefore of particular importance (Ripple et al., 2014; Wolf \& Ripple, 2017). Carnivores are also sensitive to human disturbance (Woodroffe, 200o), which is significant when setting aside areas for protection in a human-dominated landscape such as the Maasai Mara. Elephants were included because they require large home ranges and are important ecosystem engineers (De Knegt et al., 2011). As the six species have different ecological requirements, we hypothesize that their distributions will differ. Our predictions, based on key landscape variables, are summarized in Table 1.

\section{Study area}

The study was conducted in the Maasai Mara in south-west Kenya. Data were collected around the Maasai Mara National Reserve and the adjacent wildlife conservancies, hereafter 


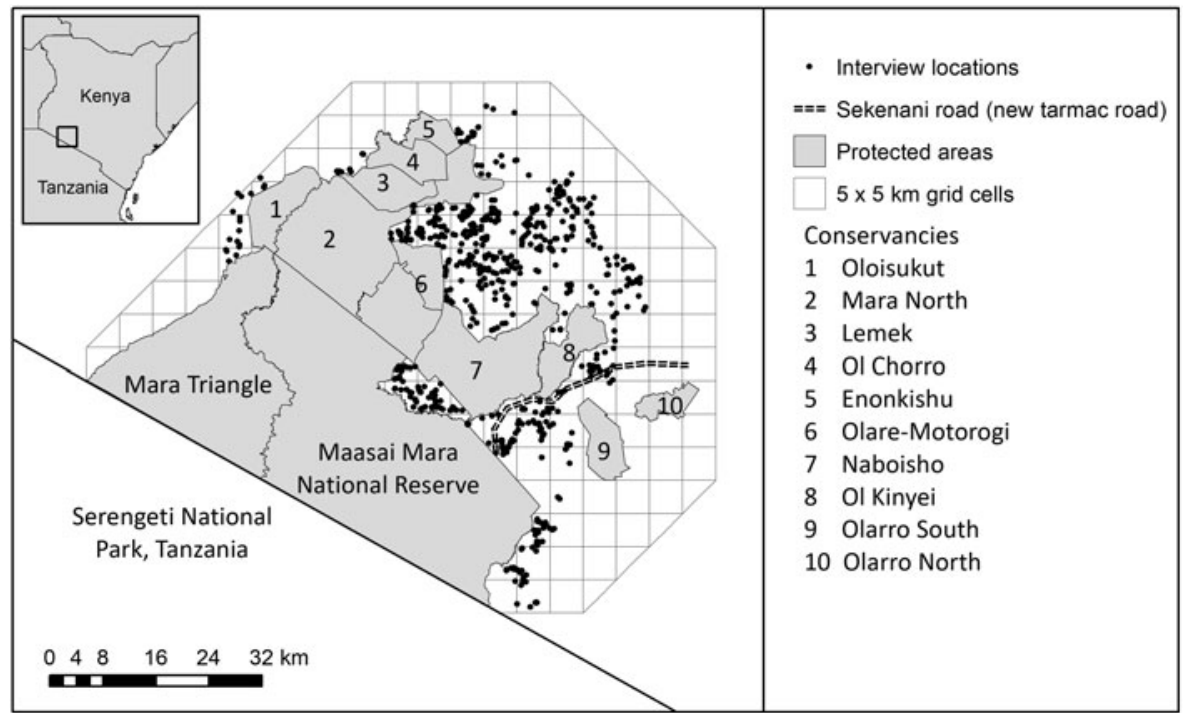

FIG. 1 Study area, showing the interview locations outside the protected areas of the Maasai Mara, Kenya, which was divided into $5 \times 5 \mathrm{~km}$ sites for the false positive occupancy analysis. 'protected areas' (Fig. 1). To the south the Reserve borders the Serengeti National Park in Tanzania, to the north and west it borders land used for intensive agriculture, and to the east lies largely pastoralist settlement (Fig. 1). There are no physical barriers between the protected areas and the surrounding community areas, allowing animals to move freely between them.

\section{Methods}

\section{Data collection}

Data on the frequency of sightings of cheetahs, elephants, spotted hyaenas, leopards, lions and wild dogs were collected through semi-structured interviews conducted in June-July 2015 by 10 Maasai men who had previous experience in conducting questionnaire-based interviews. In total, 820 interviews were conducted. In accordance with Maasai customs, the most senior male of each household was interviewed (see Broekhuis et al., 2017, for details).

A respondent's occupation could influence the amount of time spent outdoors, which in turn could affect the likelihood of seeing wildlife. Therefore, at the start of an interview respondents were asked which of the following they considered to be their main occupation: agriculturist, pastoralist, tourism, business or other. The number of respondents indicating agriculturist, business and other were low and so these were grouped together as 'other' to assist model convergence. To assess a respondent's ability to identify the species of interest they were presented with photographs of a cheetah, elephant, spotted hyaena, leopard, lion and wild dog, which they were asked to identify. Only data from respondents who correctly identified the species of interest were included in the analysis. Respondents were then asked how frequently they saw each of these species in the area of their household: yearly, monthly, weekly, daily or never. Respondents' interpretation of their area may be variable but would not be larger than $5 \times 5 \mathrm{~km}$ (Michael Kaelo, pers. comm.).

\section{Environmental variables}

Eight environmental variables, based on previous findings (Table 1), in four categories, were recorded for each site. Depending on the model selection outputs, only one variable per category was used for each species, to assist in model convergence (Petracca et al., 2018).

Human disturbance Per $5 \times 5 \mathrm{~km}$ site (see below), we calculated four measures of human disturbance using a detailed layer of human infrastructures such as buildings and livestock enclosures (see Klaassen \& Broekhuis, 2018 for details). Firstly, we calculated the mean Euclidean distance of each site to the nearest human infrastructure (hereafter human distance). We then calculated the level of human disturbance by converting the human presence polygons to a number of points that reflected the size of the development, which we then used to calculate a density using the point density function in ArcGIS 10.4.1 (ESRI, Redlands, USA), with a radius of $1,000 \mathrm{~m}$. Using this density layer we calculated the mean and sum of human disturbance for each site. Using 2015 fence data (Løvschal et al., 2017) we also calculated the proportion of area fenced per site.

Habitat type The habitat map included open, semi-closed and closed habitat types. Open habitat is mainly grasslands, semi-closed includes Vachellia (Vachellia drepanolobium and V. gerrardii) woodlands and croton Croton dichogamus 
bushes, and closed habitat is predominantly riparian. Closed and semi-closed habitat were merged, as the proportions of closed habitat were relatively low (see Klaassen \& Broekhuis, 2018, for details). The proportions of open and closed/ semi-closed habitat were then calculated for each site.

Distance to protected areas Per site, the mean Euclidean distance of the site to the protected areas was calculated.

Distance to rivers Per site, the mean Euclidian distance of the site to the nearest river was calculated.

All spatial calculations were performed in ArcGIS and all environmental variables, except those that are proportions, were standardized using a $z$-score transformation with a mean of $o$ and a standard deviation of 1 .

\section{Site-occupancy modelling}

Only interviews that were conducted outside protected areas were analysed, using a single-season occupancy model. All analyses were performed with $R$ 3.4.o (R Development Core Team, 2016) using the unmarked package (Fiske \& Chandler, 2011). The study area was divided into $5 \times 5 \mathrm{~km}$ sites, as this was a sufficiently fine scale to provide useful information for planning conservancies and corridors (Fig. 1). However, as $25 \mathrm{~km}^{2}$ is smaller than the mean home ranges of the species being assessed, this violates the assumption of closure, and therefore $\psi$ was interpreted as the probability of site use rather than the probability of occupancy (Zeller et al., 2011; Alexander et al., 2016). Other assumptions of occupancy modelling, such as no false positives and no modelled heterogeneity, are accounted for in our models. We randomly selected a maximum of 10 interviews per site to minimize variance and aid model convergence (Petracca et al., 2018) and each interview within a site was treated as a repeat survey. The potential for false positives was accounted for by introducing a binary variable, designating 1 as equal to or greater than the mean number of surveys (6) and $o$ as less than the mean, because the probability of false positives is expected to increase with the number of surveys per site (Royle \& Link, 2006; Petracca et al., 2018). The following model was used:

$$
\begin{aligned}
& L(p, \psi \mid y) \propto \prod_{i=1}^{R} 1\left\{\left[\mathrm{P}_{11}^{y_{i}}\left(1-P_{11}\right)^{T-y_{i}}\right] \psi\right. \\
&\left.+\left[\mathrm{P}_{10}^{y_{i}}\left(1-P_{10}\right) a^{T-y_{i}}\right](1-\psi)\right\}
\end{aligned}
$$

where $\mathrm{P}_{10}=$ false detection probability, $\mathrm{P}_{11}=$ true detection probability, $R=$ number of sites, $y_{i}=$ number of detections at site $i$ and $T=$ total survey number at site $i$.

To create detection histories for each site, daily and weekly sightings were considered as presence (1) and all other sightings as absence (o). However, for wild dogs, monthly sightings were also used as presence because the species is uncommon. This distinction was employed as we wished to identify sites with the highest levels of use, and daily and weekly sightings are likely to indicate an animal incorporates the site as part of its home range, whereas less frequent sightings may indicate an animal is transient.

A respondent's occupation, the proportion of open habitat, or a combination of the two, could influence the detection probability and account for heterogeneity, so each model was run separately and the variable(s) in the model with the lowest Akaike Information Criterion (AIC; Burnham \& Anderson, 2002) were used in the subsequent analysis. For the human disturbance and habitat categories, univariate models were run and the AIC values were used to determine which variable within each category best predicted site use per species. Pearson's correlation tests were run on the variables selected in the univariate analysis stage, with a threshold of $|r|>0.6$ indicating correlation (Dormann et al., 2013). Uncorrelated variables were then used in the multivariate models, which included the top variables in the human presence and habitat categories and distances to the protected areas and nearest river. A priori candidate models were ranked using AIC and relative support was assessed using the $\triangle \mathrm{AIC}$ and AIC weights. If the top model AIC weight was $<0.9$ then the probability of site use was averaged using a weighted method for all the models with $\triangle \mathrm{AIC}<2$ (Burnham \& Anderson, 2002). For models and model comparison statistics see Supplementary Material 1. The results from the top models were used to predict the probability of site use $(\psi)$ for sites without interviews using the following equation:

$$
\psi=\frac{\exp \left[\propto+\left(\beta \times D_{1}\right)+\left(\beta \times D_{2}\right) \cdots\left(\beta \times D_{5}\right)\right]}{1+\exp \left[\propto+\left(\beta \times D_{1}\right)+\left(\beta \times D_{2}\right) \cdots\left(\beta \times D_{5}\right)\right]}
$$

where $D_{1-5}=$ site use covariates and $\beta_{1-5}=$ estimated coefficients. The averaged probabilities of site use were mapped individually for each species and then summed to generate a combined map.

\section{Results}

In total 648 interviews were conducted outside the protected areas in 67 of 139 sites (1-10 interviews per site; Fig. 1). Only data where species were correctly identified were used, resulting in varying sample sizes of interviews used per species: cheetahs $n=584$, hyaenas $n=642$, leopards $n=577$, wild dogs $n=598$, lions $n=648$, and elephants $n=648$. Pearson correlation tests indicated that none of the variables in the different univariate analysis groups were correlated $(|r|<0.6)$. The false positive model was used for all species except the hyaena, for which the single-season model was used because the false positive model did not converge. Additionally, of the two models with a $\triangle$ AIC $<2$ for 
hyaenas, one did not converge so only the top model was used for prediction of site use. For all species the detection probability coefficients improved the predictive ability of the model compared to the null model. The proportion of open habitat had the best predictive ability for the probability of detecting cheetahs, lions and wild dogs. For lions the probability of detection increased with proportion of open habitat, and for wild dogs and cheetahs the probability of detection decreased, but minimally (Table 2). For elephants and leopards both the respondent's occupation and the proportion of open habitat influenced the detection probability. The proportion of open habitat increased the probability of detecting elephants, but was less important for leopards, with confidence intervals crossing zero. For hyaenas only the occupation of the respondent was in the final model.

All species except hyaenas had a habitat parameter in the final occupancy models (Table 2). In the univariate habitat covariate selection, the probabilities of site use by lions and wild dogs were best predicted by the proportion of semiclosed habitat, with both having a positive relationship, as predicted (Table 1). Site use by cheetahs, elephants and leopards, however, was best predicted by the proportion of open habitat. Probability of site use by cheetahs increased with proportion of open habitat, which was expected (Table 1), whereas the probability of site use by both elephants and leopards decreased with the proportion of open habitat. All six species were affected by human presence (Table 2). For cheetahs, lions, leopards and hyaenas the human disturbance covariate with the best fit was the mean human distance in the univariate analysis, with all showing a preference for sites further from human presence, which was expected for all species except leopards (Table 1 ). However, for both lions and leopards this effect was minimal. The probability of site use by both elephants and wild dogs decreased with an increased proportion of fences, which had the best predictive value of the human disturbance covariates. All six species contained the mean distance to protected area in their top models, with all except hyaenas decreasing in probability of site use with distance from protected area, although confidence intervals span zero for cheetahs, lions and wild dogs (Table 2). The confidence intervals for hyaenas and wild dogs also indicate that the coefficients may be zero but showed relatively even proportions in both directions. Elephants, leopards, lions and wild dogs all had the distance to nearest river in their top models, with the probability of site use decreasing with increased distance (Table 2), as predicted for these species (Table 1).

The predicted values of the probability of site use for each of the species were mapped to show their possible distributions (Fig. 2). Both elephants (mean probability of site use of 0.553 ) and hyaenas (o.910) had a wide distribution in the unprotected areas whereas leopards had the most restricted distribution (0.130). The distribution of wild dogs (o.176) appears to be in two distinct areas, in the south-east and in the north, whereas lions (0.547) and cheetahs (0.598) are present around the boundaries of the protected areas. These species-specific maps were summed to generate a combined map (Fig. 3), which highlights an important wildlife area to the east of the Maasai Mara National Reserve.

\section{Discussion}

The main aim of this study was to identify areas outside protected areas with the highest levels of use by cheetahs, elephants, spotted hyaenas, leopards, lions and wild dogs, and thus to determine key wildlife areas for future land protection schemes. We also aimed to identify the main covariates that influenced site use by each species, to aid in management decisions for these species. Site use varied greatly between species, possibly as a result of their differences in behavioural patterns and resource requirements. Distance from humans was the most informative of the human disturbance covariates for all species, indicating they avoid any human presence irrespective of density. Additionally, the two human disturbance density covariates only accounted for human disturbance within a site whereas the mean human distance also takes into account the surrounding sites. This could indicate that these species take into account human disturbance on a wider scale and not just in their vicinity. The avoidance of humans has been shown for multiple large carnivore species (e.g. Schuette et al., 2013, Klaassen \& Broekhuis, 2018) and is possibly a result of negative interactions with people (Loveridge et al., 2017). Leopards may be the exception, as they persist in many human-dominated landscapes (Athreya et al., 2013), but this was not reflected in our study, possibly because the high levels of grazing and agriculture reduce the amount of suitable habitat for them in unprotected areas or because they are difficult to detect. For elephants and wild dogs, the proportion of fences negatively influenced presence, although the effect was marginal. Previous studies have shown that fences, even though elephants have the ability to break through them, can have a strong negative impact on elephant movement (Thouless \& Sakwa, 1995; Loarie et al., 2009). The increase in fencing around the Mara (Løvschal et al., 2017) could therefore prove problematic for elephant movement. In the Mara wild dogs are rarely reported within protected areas, but they are found in humandominated areas. Our findings indicate that the presence of wild dogs is more likely to be influenced by fences than by human presence, possibly because fences restrict their wideranging behaviour. Although hyaenas strongly avoided human presence, they still had the widest distribution outside the protected areas. Other studies have shown that, rather than avoiding areas of high human and livestock 




FIG. 2 Probability of site use for the cheetah Acinonyx jubatus, elephant Loxodonta africana, spotted hyaena Crocuta crocuta, leopard Panthera pardus, lion Panthera leo and wild dog Lycaon pictus outside the protected areas of the Maasai Mara (Fig. 1). Sites (grid cells) are $5 \times 5 \mathrm{~km}$. presence, hyaenas change their activity patterns, and this behavioural plasticity could explain their distribution (Kolowski et al., 2007; Kolowski \& Holekamp, 2009).

Habitat covariates differed markedly between the six species, perhaps related to resource requirements and different hunting strategies. The presence of cheetahs was influenced by the proportion of open habitat, aligning with previous findings that cheetahs use grasslands, as they are cursorial hunters (Bissett \& Bernard, 2007; Broekhuis et al., 2013). Lions and leopards, which are stalk and ambush hunters, preferred semi-closed habitat, similar to findings from other areas (Hopcraft et al., 2005; Balme et al., 2007). In addition, for leopards the presence of trees in the semi-closed habitat provides opportunities to cache food and reduce kleptoparasitism (Balme et al., 2007, 2017a). Similarly, wild dogs selected semi-closed habitat, possibly to minimize detection and reduce the risk of kleptoparasitism (Creel \& Creel, 1998; Carbone et al., 2005). Other studies have shown that hyaenas select for semi-closed habitat and avoid open areas (Kolowski \& Holekamp, 2009). This was not reflected in our findings, possibly a result of habitat selection not being sufficiently strong at the scale of the study. Elephants preferred semi-closed over open habitat, which is probably related to the availability of browse or the result of a desire to minimize detection and avoid livestock, which often graze in open habitat (Galanti et al., 2006).

Site use for all species except hyaenas decreased with increased distance from the protected areas. This is not surprising as various studies have shown that species such as elephants and cheetahs prefer to use areas in, or close to, protected areas (Douglas-Hamilton et al., 2005; Galanti et al., 2006; Klaassen \& Broekhuis, 2018). For hyaenas this 


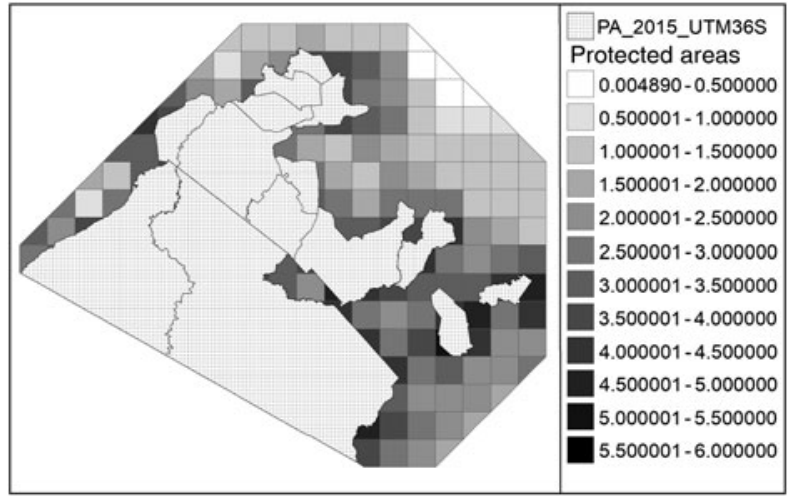

FIG. 3 Combined probability of site use values for the six species (the cheetah, elephant, hyaena, leopard, lion and wild dog;

Fig. 2), outside the protected areas of the Maasai Mara (Fig. 1).

may not be the case as they are able to persist in humandominated areas outside protected areas.

Rivers influenced the presence of lions, leopards, wild dogs and elephants and this could be related to the dense vegetation found beside rivers. Leopards, wild dogs and lions have been shown to select for similar habitats, including rivers, as they provide a cool environment during the day, denning opportunities for females with offspring, and increased hunting opportunities (Spong, 2002). De Knegt et al. (2011) theorized that, on a fine scale, elephants do not always need to be close to a water source as long as there is one within a day's walking distance. In the Mara, water sources are fairly common and accessible and therefore water availability is unlikely to be a limiting factor. It is therefore likely that the selection for rivers is a reflection of the habitat type occurring beside them.

The individual species distribution maps are supported by both sightings and data collected by GPS collars, in particular those that have been fitted on cheetahs (Klaassen \& Broekhuis, 2018) and wild dogs (Masenga et al., 2016). Lions have a much wider distribution than leopards, despite these species selecting for similar habitat (Balme et al., 2017b) and this probably reflects the higher densities at which lions occur in the Mara (Elliot \& Gopalaswamy, 2017). Cheetahs and lions occur in similar areas and, although lions are a direct threat to cheetahs, these species can co-exist through fine-scale avoidance behaviour (Broekhuis et al., 2013). The inverse distribution of wild dogs and lions is similar to findings from Botswana (Cozzi, 2012) and South Africa (Darnell et al., 2014). Such avoidance behaviour affects the patterns of co-occurrence (MacKenzie et al., 2004). This illustrates the importance of taking a multi-species, rather than a single species, approach to management as the expansion of protected areas could increase lion presence and numbers, which could have a negative impact on the population of wild dogs in the Mara. Potential species interactions therefore need to be taken into account when considering management practices.
The combined map shows that site use is highest east and north of the protected areas. Compared to other areas with a similar distance to protected areas, the area north of Naboisho and east of Olare-Motorogi conservancies (also known as the Pardamat Plains) had a low level of site use by all six species. This is probably because the open habitat provides little cover for wildlife. The area south of Naboisho and $\mathrm{Ol}$ Kinyei conservancies appears to have the highest site use for all species. This could prove problematic as the Sekanani road, which passes through this area, was, at the time of writing, being tarmacked. This could have negative consequences for the dispersal and movement of these species, and others, unless adequately mitigated.

The covariates used in this study were on a relatively broad scale and it is possible that there are others affecting wildlife distribution on a finer scale. For example, elephants have been shown to have seasonal habitat preferences and fine scale preferences with respect to plant composition (Galanti et al., 2006; Shannon et al., 2006). Gradient and elevation, which were not taken into account in this study, influence leopard site use (Balme et al., 2017b). There could also be other factors that affect the respondents' probability of seeing a species: not all pastoralists will spend equal amounts of time with their livestock. One potential limitation of our study is that it was difficult to ensure that the interviewees reported only on their site and did not include sightings from other areas. However, the false positive model should have accounted for the potential for a small number of interviewees reporting on a wider area than intended.

Interview methodology provides an opportunity to rapidly assess the distribution of wildlife in unprotected areas and has the potential to be developed into a long-term monitoring programme. The use of the false positive model increases the robustness of the results derived from untrained individuals (Petracca et al., 2018). In general, our findings corroborate published literature and expert opinion. We recommend the areas to the east, between the main protected areas and the outer conservancies, which have the highest level of use, as a conservation priority, which could include the expansion of current conservancies and the creation of new conservancies and wildlife corridors. This is particularly important in light of the increasing development in this area, including the erection of fences (Løvschal et al., 2017) and the tarmacking of a main road that passes through this region. However, increasing the amount of protected land can have a negative conservation outcome if local people become resentful, especially if they are displaced or access to resources is restricted. For successful conservation, land protection schemes need to take into account the needs of both wildlife and people (Roe, 2008).

Acknowledgements A component of this study was carried out in fulfilment of the Wild Animal Biology MSc (EKM) at the Royal Veterinary College and the Zoological Society of London. We thank 
the National Council for Science and Technology, Narok County Government and the Maasai Mara Wildlife Conservancies Association for permission to carry out this study, Basecamp Foundation Kenya for providing funding to allow us to conduct the interviews, and private donors who made donations to the Kenya Wildlife Trust. We also thank the 10 interviewers, the respondents for volunteering their time, Fiona Tande for assisting with data entry, Sam Turvey for advice on using interview data, Lisanne Petracca for advice on site-occupancy modelling, and the reviewers for their useful comments.

Author contributions Concept and design: FB; supervision of data collection: FB; data validation: FB and EKM; analysis: EKM; writing: EKM; revision and editing: FB.

\section{Conflicts of interest None.}

Ethical standards Surveys followed the Zoological Society of London's guidelines and methods were approved by Society's Ethical Committee.

\section{References}

Alexander, J.S., Gopalaswamy, A.M., Shi, K., Hughes, J. \& Riordan, P. (2016) Patterns of snow leopard site use in an increasingly human-dominated landscape. PLoS ONE, 11(5), e0155309.

Athreya, V., Odden, M., Linnell, J.D.C., Krishnaswamy, J. \& KarAnth, U. (2013) Big cats in our backyards: persistence of large carnivores in a human dominated landscape in India. PLoS ONE, 8 (3), e57872.

Balme, G., Hunter, L. \& Slotow, R. (2007) Feeding habitat selection by hunting leopards Panthera pardus in a woodland savanna: prey catchability versus abundance. Animal Behaviour, 74, 589-598.

Balme, G.A., Miller, J.R., Pitman, R.T. \& Hunter, L.T. (2017a) Caching reduces kleptoparasitism in a solitary, large felid. Journal of Animal Ecology, 86, 634-644.

Balme, G.A., Pitman, R.T., Robinson, H.S., Miller, J.R.B., Funston, P.J. \& Hunter, L.T.B. (2017b) Leopard distribution and abundance is unaffected by interference competition with lions. Behavioral Ecology, 28, 1348-1358.

Bissett, C. \& Bernard, R.T.F. (2007) Habitat selection and feeding ecology of the cheetah (Acinonyx jubatus) in thicket vegetation: is the cheetah a savanna specialist?. Journal of Zoology, 271, 310-317.

Broekhuis, F., Cozzi, G., Valeix, M., McNutt, J.W. \& Macdonald, D.W. (2013) Risk avoidance in sympatric large carnivores: reactive or predictive? Journal of Animal Ecology, 82, 1098-1105.

Broekhuis, F., Cushman, S.A. \& Elliot, N.B. (2017) Identification of human-carnivore conflict hotspots to prioritise mitigation efforts. Ecology and Evolution, 7, 10630-10639.

Broekhuis, F. \& Gopalaswamy, A.M. (2016) Counting cats: spatially explicit population estimates of cheetah (Acinonyx jubatus) using unstructured sampling data. PLoS ONE, 11(5), e0153875.

Burnham, K.P. \& Anderson, D.R. (2002) Model Selection and Multimodel Inference: A Practical Information-Theoretic Approach. Springer-Verlag, New York, USA.

Carbone, C., Frame, L., Frame, G., Malcolm, J., Fanshawe, J., FitzGibвon, C. et al. (2005) Feeding success of African wild dogs (Lycaon pictus) in the Serengeti: the effects of group size and kleptoparasitism. Journal of Zoology, 266, 153-161.
CozzI, G. (2012) Patterns of habitat use and segregation among African large carnivores: a case study on the African wild dog (Lycaon pictus), the spotted hyena (Crocuta crocuta), and the lion (Panthera leo). $\mathrm{PhD}$ thesis. University of Zurich, Zurich, Switzerland.

Creel, S. \& Creel, N.M. (1998) Six ecological factors that may limit African wild dogs, Lycaon pictus. Animal Conservation, 1, 1-9.

Darnell, A.M., Graf, J.A., Somers, M.J., Slotow, R. \& Szykman Gunther, M. (2014) Space use of African wild dogs in relation to other large carnivores. PLoS ONE, 9(6), e98846.

de Knegt, H.J., van Langevelde, F., Skidmore, A.K., Delsink, A., Slotow, R., Henley, S. et al. (2011) The spatial scaling of habitat selection by African elephants: scaling habitat selection by elephants. Journal of Animal Ecology, 8o, 270-281.

Dormann, C.F., Elith, J., Bacher, S., Buchmann, C., Carl, G., CARRÉ, G. et al. (2013) Collinearity: a review of methods to deal with it and a simulation study evaluating their performance. Ecography, $36,27-46$.

Douglas-Hamilton, I., Krink, T. \& Vollrath, F. (2005) Movements and corridors of African elephants in relation to protected areas. Naturwissenschaften, 92, 158-163.

Elliot, N.B. \& Gopalaswamy, A.M. (2017) Toward accurate and precise estimates of lion density. Conservation Biology, 31, 934-943.

Fiske, I. \& Chandler, R. (2011) Unmarked: an $R$ package for fitting hierarchical models of wildlife occurrence and abundance. Journal of Statistical Software, 43, 1-23.

Galanti, V., Preatoni, D., Martinoli, A., Wauters, L. \& Tosi, G. (2006) Space and habitat use of the African elephant in the Tarangire-Manyara ecosystem, Tanzania: implications for conservation. Mammalian Biology-Zeitschrift für Säugetierkunde, 71, 99-114.

Gu, W. \& SwiHart, R.K. (2004) Absent or undetected? Effects of non-detection of species occurrence on wildlife-habitat models. Biological Conservation, 116, 195-203.

Hopcraft, J.G.C., Sinclair, A.R.E. \& Packer, C. (2005) Planning for success: Serengeti lions seek prey accessibility rather than abundance. Journal of Animal Ecology, 74, 559-566.

Jandreau, C. \& Berkes, F. (2016) Continuity and change within the social-ecological and political landscape of the Maasai Mara, Kenya. Pastoralism, 6, 1 .

Klatissen, B. \& Broekhuis, F. (2018) Living on the edge: multiscale habitat selection by cheetahs in a human-wildlife landscape. Ecology and Evolution, https://doi.org/10.1002/ece3.4269.

Kolowski, J.M. \& Holekamp, K.E. (2009) Ecological and anthropogenic influences on space use by spotted hyaenas. Journal of Zoology, 277, 23-36.

Kolowski, J.M., Katan, D., Theis, K.R. \& Holekamp, K.E. (2007) Daily patterns of activity in the spotted hyena. Journal of Mammalogy, 88, 1017-1028.

LAmprey, R.H. \& Reid, R.S. (2004) Expansion of human settlement in Kenya's Maasai Mara: what future for pastoralism and wildlife? Journal of Biogeography, 31, 997-1032.

Loarie, S.R., A Arde, R.J.V. \& Pimm, S.L. (2009) Fences and artificial water affect African savannah elephant movement patterns. Biological Conservation, 142, 3086-3098.

Loveridge, A.J., Valeix, M., Elliot, N.B. \& Macdonald, D.W. (2017) The landscape of anthropogenic mortality: how African lions respond to spatial variation in risk. Journal of Applied Ecology, 54, $815-825$.

Løvschal, M., Bøcher, P.K., Pilgaard, J., Amoke, I., Odingo, A., Thuo, A. \& Svenning, J.-C. (2017) Fencing bodes a rapid collapse of the unique Greater Mara ecosystem. Scientific Reports, 7, 41450.

MacKenzie, D.I., Bailey, L.L. \& Nichols, J. (2004) Investigating species co-occurrence patterns when species are detected imperfectly. Journal of Animal Ecology, 73, 546-555. 
MacKenzie, D.I., Nichols, J.D., Lachman, G.B., Droege, S., Andrew Royle, J. \& Langtimm, C.A. (2002) Estimating site occupancy rates when detection probabilities are less than one. Ecology, 83, 2248-2255.

MacKenzie, D.I., Nichols, J.D., Hines, J.E., Knutson, M.G. \& FrankLIN, A.B. (2003) Estimating site occupancy, colonization, and local extinction when a species is detected imperfectly. Ecology, 84, 2200-2207.

Masenga, E.H., Jackson, C.R., Mjingo, E.E., Jacobson, A., Riggio, J., LyamuYa, R.D. et al. (2016) Insights into long-distance dispersal by African wild dogs in East Africa. African Journal of Ecology, 54, 95-98.

Miller, D.A., Nichols, J.D., McClintock, B.T., Grant, E.H.C., BAILEY, L.L. \& WEIR, L.A. (2011) Improving occupancy estimation when two types of observational error occur: non-detection and species misidentification. Ecology, 92, 1422-1428.

MMWCA (Maasai Mara Wildlife Conservancies Association) (2015) Cultural and Natural Resources Conservation Action Plan Briefing Paper. Https://www.maraconservancies.org/ wp-content/uploads/2017/05/MMWCA-Conservation-ActionPlan-Briefing-Paper1.pdf [accessed 23 June 2018].

Ogutu, J.O., Owen-Smith, N., Piepho, H.P. \& SAid, M.Y. (2011) Continuing wildlife population declines and range contraction in the Mara region of Kenya during 1977-2009. Journal of Zoology, 285, 99-109.

Okello, M.M., Kenana, L., Maliti, H., Kiringe, J.W., Kanga, E., Warinwa, F. et al. (2016) Population density of elephants and other key large herbivores in the Amboseli ecosystem of Kenya in relation to droughts. Journal of Arid Environments, 135, 64-74.

Petracca, L.S., Frair, J.L., Cohen, J.B., Calderón, A.P., Carazo-Salazar, J., Castañeda, F. et al. (2018) Robust inference on large-scale species habitat use with interview data: the status of jaguars outside protected areas in Central America. Journal of Applied Ecology, 55, 723-734.

Pillay, R., Johnsingh, A.J.T., Raghunath, R. \& Madhusudan, M. D. (2011) Patterns of spatiotemporal change in large mammal distribution and abundance in the southern Western Ghats, India. Biological Conservation, 144, 1567-1576.

Pulliam, H.R. (1988) Sources, sinks, and population regulation. The American Naturalist, 132, 652-661.

R Development Core Team (2016) R: A Language and Environment for Statistical Computing. R Foundation for Statistical Computing, Vienna, Austria. Https://www.r-project.org/ [accessed June 2017].

Republic of Kenya (2013) Kenya Gazette Supplement No. 181 (Acts No. 47). Http://www.kws.go.ke/file/wildlife-conservation-andmanagement-bill-2013pdf [accessed 23 June 2018].
Ripple, W.J., Estes, J.A., Beschta, R.L., Wilmers, C.C., Ritchie, E. G., Hebblewhite, M. et al. (2014) Status and ecological effects of the world's largest carnivores. Science, 343, 1241484.

Roe, D. (2008) The origins and evolution of the conservation-poverty debate: a review of key literature, events and policy processes. Oryx, 42, 491-503.

Royle, J.A. \& Link, W.A. (2006) Generalized site occupancy models allowing for false positive and false negative errors. Ecology, 87, 835-841.

Schuette, P., Wagner, A.P., Wagner, M.E. \& Creel, S. (2013) Occupancy patterns and niche partitioning within a diverse carnivore community exposed to anthropogenic pressures. Biological Conservation, 158, 301-312.

Shannon, G., Page, B., Slotow, R. \& Duffy, K. (2006) African elephant home range and habitat selection in Pongola Game Reserve, South Africa. African Zoology, 41, 37-44.

Spong, G. (2002) Space use in lions, Panthera leo, in the Selous Game Reserve: social and ecological factors. Behavioral Ecology and Sociobiology, 52, 303-307.

Stokes, E.J., Strindberg, S., Bakabana, P.C., Elkan, P.W., Iyenguet, F.C., Madzoké, B. et al. (2010) Monitoring great ape and elephant abundance at large spatial scales: measuring effectiveness of a conservation landscape. PLoS ONE, 5(4), e10294.

Stolton, S., Redford, K.H. \& Dudley, N. (2014) The Futures of Privately Protected Areas. Protected Area Technical Report Series No.1. IUCN, Gland, Switzerland.

Thouless, C.R. \& SAKWA, J. (1995) Shocking elephants: fences and crop raiders in Laikipia District, Kenya. Biological Conservation, 72, 99-107.

Turvey, S.T., Trung, C.T., Quyet, V.D., Nhu, H.V., Thoai, D.V., TUAN, V.C.A. et al. (2015) Interview-based sighting histories can inform regional conservation prioritization for highly threatened cryptic species. Journal of Applied Ecology, 52, 422-433.

Western, D., Russell, S. \& Cuthill, I. (2009) The status of wildlife in protected areas compared to non-protected areas of Kenya. PLoS ONE, 4(7), e6140.

Wolf, C. \& Ripple, W.J. (2017) Range contractions of the world's large carnivores. Royal Society Open Science, 4, 170052.

Woodroffe, R. \& GinsberG, J. R. (1998) Edge effects and the extinction of populations inside protected areas. Science, 28o, 2126-2128.

Woodroffe, R. (200o) Predators and people: using human densities to interpret declines of large carnivores. Animal Conservation, 3 , 165-173.

Zeller, K.A., Nijhawan, S., Salom-Pérez, R., Potosme, S.H. \& HinES, J.E. (2011) Integrating occupancy modeling and interview data for corridor identification: a case study for jaguars in Nicaragua. Biological Conservation, 144, 892-901. 